STUDI

FRANCESI

\section{Studi Francesi}

Rivista quadrimestrale fondata da Franco Simone

185 (LXII | II) | 2018

OCTAVE MIRBEAU: UNE CONSCIENCE AU TOURNANT

DU SIEECLE - sous la direction de Ida Merello

\title{
Gautier et Nerval. Collaborations, solidarités, différences, textes réunis par Anne GEISLER-SZMULEWICZ et Sarga MOUSSA
}

\section{Aurélia Cervoni}

\section{(2) OpenEdition}

\section{Journals}

Édition électronique

URL : https://journals.openedition.org/studifrancesi/13839

DOI : 10.4000/studifrancesi. 13839

ISSN : 2421-5856

Éditeur

Rosenberg \& Sellier

\section{Édition imprimée}

Date de publication : 1 août 2018

Pagination : 344

ISSN : 0039-2944

\section{Référence électronique}

Aurélia Cervoni, «Gautier et Nerval. Collaborations, solidarités, différences, textes réunis par Anne GeISLERszmulewicz et sarga moussa », Studi Francesi [En ligne], 185 (LXII | II) | 2018, mis en ligne le 01 août 2018, consulté le 15 novembre 2021. URL : http://journals.openedition.org/studifrancesi/13839; DOI :

https://doi.org/10.4000/studifrancesi.13839

Ce document a été généré automatiquement le 15 novembre 2021.

\section{(c) $(1) \odot$}

Studi Francesi è distribuita con Licenza Creative Commons Attribuzione - Non commerciale - Non opere derivate 4.0 Internazionale. 


\title{
Gautier et Nerval. Collaborations, solidarités, différences, textes réunis par Anne GEISLER-SZMULEWICZ et sarga MOUSSA
}

\author{
Aurélia Cervoni
}

\section{RÉFÉRENCE}

Gautier et Nerval. Collaborations, solidarités, différences, textes réunis par Anne GEISLER-

SZMULEWICZ et sarga MOUSSA, «Bulletin de la Société Théophile Gautier» 38, 2016, 148 pp.

1 Les affinités entre Gautier et Nerval ont fait l'objet d'une trentaine de travaux, pour la plupart des articles. Le «Dossier» du «Bulletin de la Société Théophile Gautier» numéro 38 est la première entreprise de réflexion collective sur ce sujet; il rassemble les actes d'une journée d'étude qui s'est tenue le 27 novembre 2015 à la Maison de Balzac, à l'initiative de la Société Théophile Gautier. Il comprend sept articles, qui sont autant de mises au point érudites et attentives aux subtilités du texte.

2 Le premier, par Michel BRIX (Jeunes-France, Bousingots, Tartares et... Cochons, pp. 13-26), reproduit deux documents importants datés du 20 mars et du 5 avril 1832, découverts récemment par Jean-Claude Féray dans les archives de la préfecture de police de Paris, et qui témoignent de la méfiance de la police de la monarchie de Juillet à l'égard du Petit Cénacle. Les articles suivants sont consacrés à des questions d'attribution et d'intertextualité. Anne GEISLER-SZMULEWICZ (Gautier, Nerval et l'excentricité jeune France. À propos du motif de la conversion romantique, pp. 27-45), souligne les points de convergence entre deux contes d'inspiration Jeune-France, La Main de gloire de Nerval et Onuphrius de Gautier. Corinne BAYLE (Gautier, Nerval, et les Cydalises. Figurations de la Poésie, entre image et voix, pp. 47-61) relit les œuvres et les souvenirs des deux auteurs en prenant pour guide la figure de la Cydalise, qui fut la muse de la bohème du Doyenné. François BRUNET 
("Le Bonheur de la maison": un problème d'attribution, pp. 63-74) développe une hypothèse séduisante: Le Bonheur de la maison, publié par Nerval en 1831 et présenté comme un fragment traduit de Jean-Paul, serait en réalité l'œuvre de Gautier, qui en reproduit des phrases entières dans L'Âme de la maison (1839). Patrick BERTHIER («G.-G.»: réflexions sur une signature, pp. 75-88) revient sur la "fraternité stylistique, humoristique et satirique» des deux auteurs et dresse un bilan des difficultés rencontrées par les éditeurs pour identifier les parties rédigées par Nerval et les parties rédigées par Gautier dans les critiques dramatiques signées «G.-G.». Hélène LAPLACE-CLAVERIE (Gautier et Nerval, frères de théâtre, pp. 89-101) montre que Gautier et Nerval, admirateurs de Molière, nourrissaient le même fantasme d'un "théâtre fantastique, extravagant, impossible», selon la formule de d'Albert dans Mademoiselle de Maupin. Sarga Moussa (Le Caire rêvé, Le Caire parodié. Gautier et Nerval, correspondance croisée [1843], pp. 103-116) voit dans l'image de l'Égypte, idéalisée sous la plume de Gautier, plus contrastée voire parodique dans l'œuvre de Nerval, le symptôme d'un «malaise» de la civilisation française, lié à l'instabilité politique et à l'essor de la philosophie du progrès.

3 Le «Bulletin de la Société Théophile Gautier» numéro 38 comporte en outre une rubrique «Varia». On pourra y lire une étude suggestive d'Anne GEISLER-SZMULEWICZ ("Quand la mort des animaux devient spectacle»: excursions à Montfaucon, pp. 119-134) sur la «beauté de l'horrible», telle que Gautier l'a dépeinte dans le récit de ses visites à Montfaucon, et une Petite chronique bibliographique (pp.134-142), qui rend compte de trois publications relatives à la correspondance et à la critique théâtrale de Gautier. 